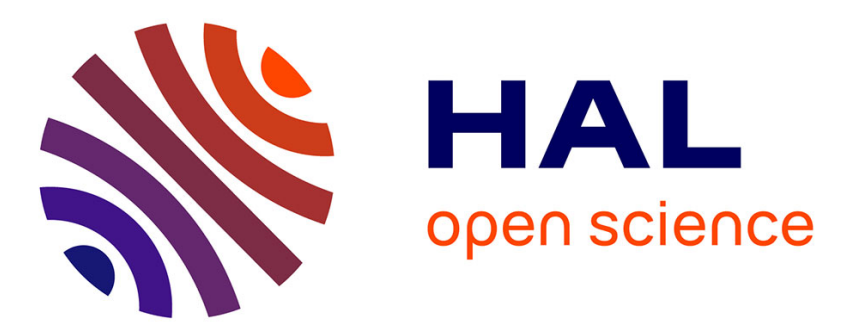

\title{
Functionalization of Reduced Graphene Oxide via Thiol-Maleimide "Click" Chemistry: Facile Fabrication of Targeted Drug Delivery Vehicles
}

\author{
Yavuz Oz, Alexandre Barras, Rana Sanyal, Rabah Boukherroub, Sabine \\ Szunerits, Amitav Sanyal
}

\section{To cite this version:}

Yavuz Oz, Alexandre Barras, Rana Sanyal, Rabah Boukherroub, Sabine Szunerits, et al.. Functionalization of Reduced Graphene Oxide via Thiol-Maleimide "Click" Chemistry: Facile Fabrication of Targeted Drug Delivery Vehicles. ACS Applied Materials \& Interfaces, 2017, 9 (39), pp.34194 - 34203. 10.1021/acsami.7b08433 . hal-01804945

\section{HAL Id: hal-01804945 \\ https://hal.science/hal-01804945}

Submitted on 1 Jun 2018

HAL is a multi-disciplinary open access archive for the deposit and dissemination of scientific research documents, whether they are published or not. The documents may come from teaching and research institutions in France or abroad, or from public or private research centers.
L'archive ouverte pluridisciplinaire HAL, est destinée au dépôt et à la diffusion de documents scientifiques de niveau recherche, publiés ou non, émanant des établissements d'enseignement et de recherche français ou étrangers, des laboratoires publics ou privés. 


\section{Functionalization of Reduced Graphene Oxide via Thiol-Maleimide "Click" Chemistry: Facile Fabrication of Targeted Drug Delivery Vehicles}

Authors: Yavuz Oz ${ }^{1}$, Alexandre Barras ${ }^{3}$, Rana Sanyal ${ }^{124}$, Rabah Boukherroub ${ }^{3}$, Sabine Szunerits* ${ }^{3}$, and Amitav Sanyal* ${ }^{12}$

${ }^{1}$ Department of Chemistry and ${ }^{2}$ Center for Life Sciences and Technologies, Bogazici University, Bebek, 34342 Istanbul, Turkey

${ }^{3}$ Université Lille, CNRS, Centrale Lille, ISEN, Université Valenciennes, UMR 8520-IEMN, F-59000 Lille, France

${ }^{4}$ RS Research Inc., Teknopark Istanbul, Pendik, 34912 Istanbul, Turkey

First published: 14/09/2017

DOI: 10.1021/acsami.7b08433

Abstract.
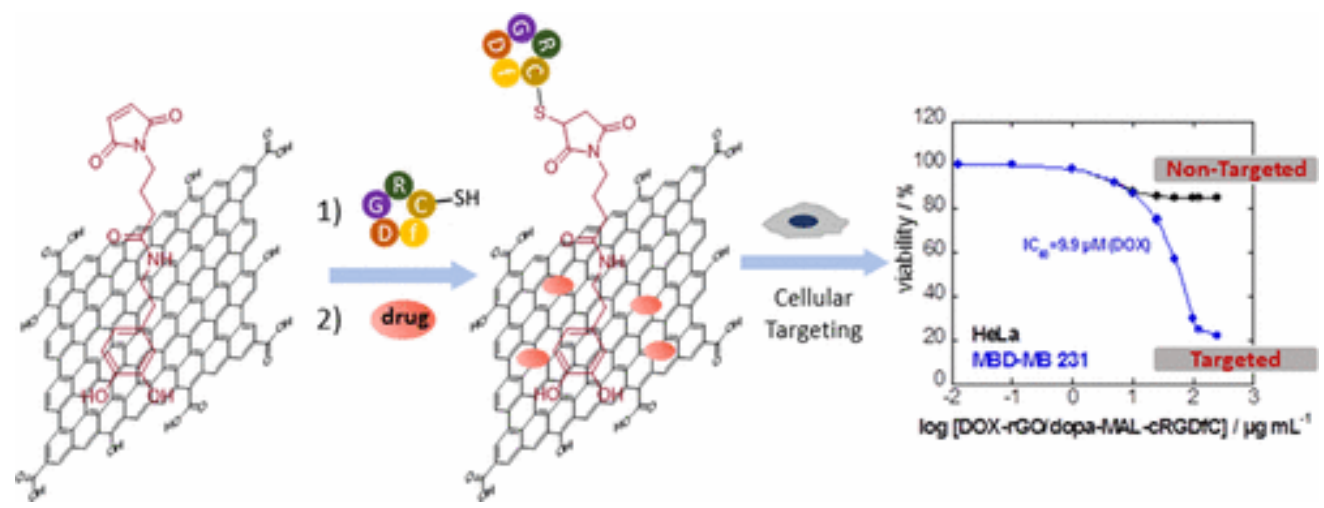

Materials based on reduced graphene oxide (rGO) have shown to be amenable to noncovalent functionalization through hydrophobic interactions. The scaffold, however, does not provide sufficient covalent linkage given the low number of reactive carboxyl and alcohol groups typically available on the rGO. The integration of clickable groups, particularly the ones that can undergo efficient conjugation without any metal catalyst, would allow facile functionalization of these materials. This study reports on the noncovalent association of a maleimide-containing catechol (dopa-MAL) surface anchor onto the rGO. Thiol-maleimide chemistry allows thereafter the facile attachment of thiol-containing molecules under ambient metal-free conditions. Although the attachment of glutathione and 6-(ferrocenyl)hexanethiol 
was used as model thiols, the attachment of a cancer cell targeting cyclic peptide, c(RGDfC), opened the possibility of using the dopa-MAL-modified rGO as a targeted drug delivery system for doxorubicin (DOX). Although free DOX showed to be more effective at killing the human cervical cancer cells (HeLa) over human breast adenocarcinoma cancer cells (MDAMB-231), the DOX-loaded rGO/dopa-MAL-c (RGDfC) nanostructure showed an opposite effect being notably more effective at targeting and killing the MDA-MB-231 cells. The effect is enhanced upon laser irradiation for $10 \mathrm{~min}$ at $2 \mathrm{~W} \mathrm{~cm}$. The facile fabrication and functionalization to readily obtain a functional material in a modular fashion make this clickable-rGO construct an attractive platform for various applications.

\section{Keywords:}

cellular targeting; click chemistry; DOX delivery; graphene oxide; photothermal effect; $\underline{\text { thiol-maleimide conjugation }}$

\section{Introduction}

Nanosystems that release cancer drugs and induce toxicity in response to an external stimulus offer unique advantages over the commonly employed conventional carriers that release their payload in a passive fashion. Reduced graphene oxide ( $\mathrm{rGO}$ ) nanosheets with restored $\mathrm{sp}^{2}$ network have most lately shown to be ideally suited for drug-loading- and drug-release-based applications using electrical(1-3) as well as thermal induced triggers.(4-10) Although the majority of the aromatic scaffold of rGO is devoid of any functional groups, a few carboxylic acid and alcohol groups are present at the edges and other defect points. This limits the effective functionalization of the $\mathrm{rGO}$ through covalent transformations. To circumvent this limitation, the noncovalent $\pi-\pi$ stacking-based functionalization route of the rGO scaffold has been extensively exploited.(11-16) This approach is effective for hydrophobic/aromatic molecules that are able to undergo efficient noncovalent interactions. Conjugation of molecules unable to undergo such an association with the rGO, however, becomes challenging. An approach that would allow facile and effective covalent attachment in a modular manner to the rGO would be rather useful.

Aromatic anchoring groups like pyrene, $(11,17)$ tetrathiafulvalene $(13,15)$ and dopamine derivatives $(14,16)$ have shown to be of high interest for rGO functionalization. Some of us have reported surface functionalization of the $\mathrm{rGO}$ with dopamine-containing clickable alkyne and azide groups. $(14,16)$ The azide-containing rGO could be further modified with alkynylterminated molecules such as ferrocene via the $\mathrm{Cu}(\mathrm{I})$-catalyzed azide-alkyne Huisgen-type click reaction. Although the azide-alkyne-based rGO functionalization was effective, the requirement to use copper as a catalyst can be a concern for the biomedical applications because any trace of copper adds to the overall cytotoxicity of the nanostructures. This necessitates the expansion of the tool box to include click reactions that do not need metal catalysts, like the strain-promoted azide-alkyne cycloaddition (SPAAC)(18) and the nucleophilic or radical thiol-ene reactions. $(16,19)$ Although approaches based on SPAAC have gained interest lately,(20) the multistep synthesis or high cost of the cyclooctyne-based materials limits the widespread utilization of this approach. Nucleophilic thiol-ene-based reactions have been extensively employed in the bioconjugations using the thiol-maleimide functional group dyad and seem advantageous.(21-24) The maleimide-thiol addition reaction is a facile process that does not require any catalyst and can be carried out under mild

DOI: 10.1021/acsami.7b08433 - Journal: ACS Appl. Mater. Interfaces - Post-print 
conditions. Although thiol groups can be readily incorporated in various molecules, they are also present in the cysteine residue of various peptides and biomolecules, or can be installed using standard protocols during or after synthesis.

Herein, we report the synthesis of a maleimide functional group containing the $\mathrm{rGO}$, which is amenable to facile functionalization by thiol group containing molecules (Scheme 1). The conjugation of thiol-bearing molecules proceeds through the thiol-ene click-type conjugation reaction, under metal-free conditions. Maleimide functionalized rGO was easily prepared through $\pi-\pi$ interactions under ultrasonication of the rGO with a maleimide-containing dopamine (dopa-MAL) ligand. To demonstrate the utility of this clickable rGO, we took the advantage of the covalent conjugation of a thiol-bearing targeting peptide, c(RGDfC), and the noncovalent loading of the $\mathrm{rGO}-\mathrm{c}(\mathrm{RGDfC})$ nanostructures with the anticancer drug doxorubicin (DOX). The two-dimensional structure of graphene sheets serves as an excellent drug carrier due to its high drug loading capacity arising from the $\pi-\pi$ stacking and other hydrophobic interactions. Attachment of a targeting group on the rGO through covalent conjugation further expands its application to the targeted drug delivery. Selective delivery of anticancer agents to the tumor site has become important for efficient cancer therapy by minimizing the negative side effects. Synthetic cyclic peptides with arginine-glycine-aspartic acid sequences (RGDs) are known to possess high affinity to integrin $\alpha_{\mathrm{v}} \beta_{3}$, a cell adhesion domain highly expressed on the tumor cells. $(25,26)$ Their integration into the nanostructures and polymers for targeted drug delivery has thus found growing interest.(27, 28)

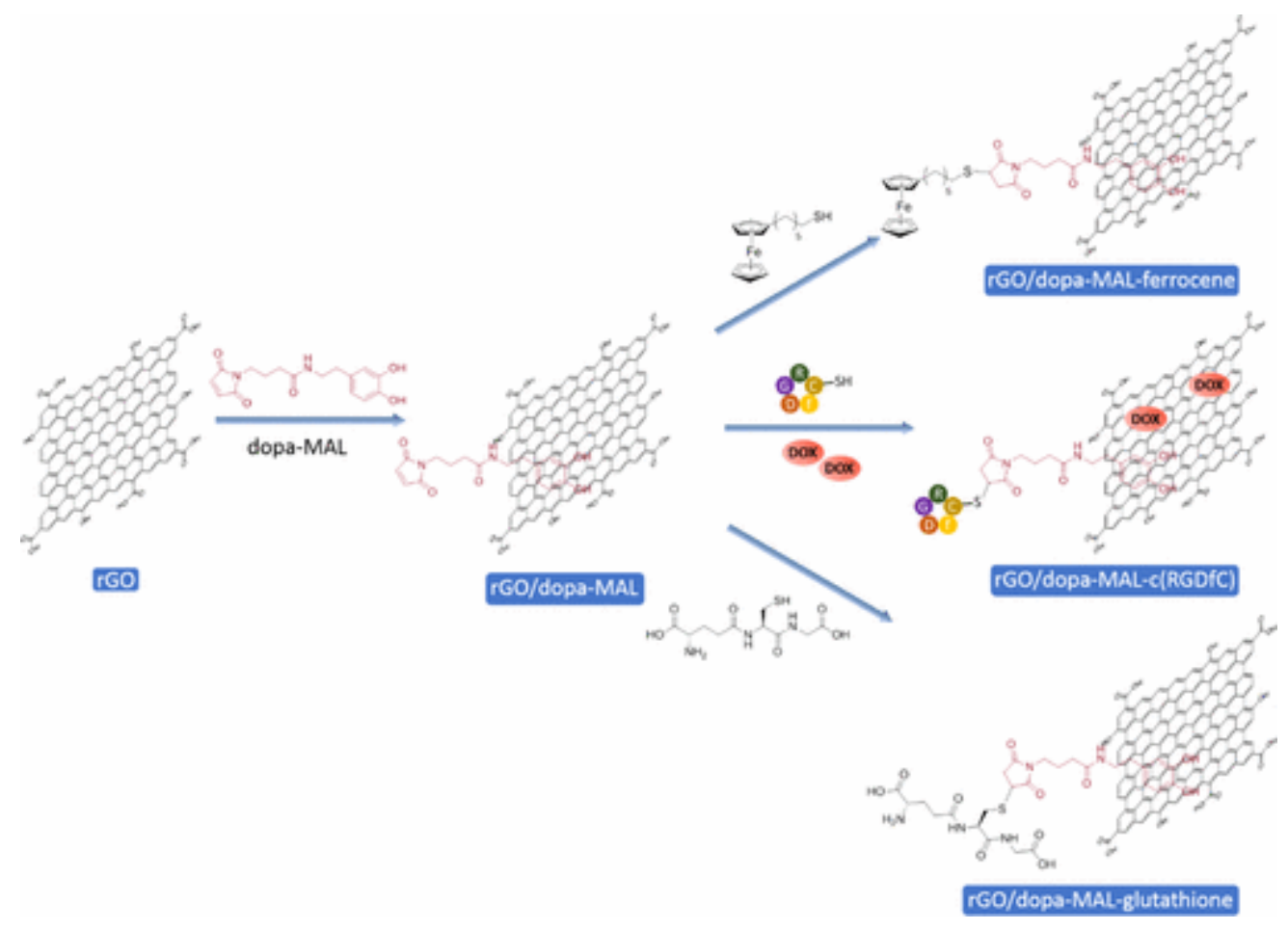

Scheme 1. Schematic Illustration of the Synthesis of Thiol-Ene "Clickable" Maleimide-rGO and its Subsequent Functionalization 
Finally, the excellent photothermal properties of DOX-loaded rGO/dopa-MAL-c(RGDfC) allow for chemophototherapy; the combination of photothermal therapy with chemotherapeutic release of DOX is often beneficial specifically for solid tumors.(29) The cytotoxicity of targeted and nontargeted rGO under normal and photothermal conditions was assessed on two cancer cell lines, human breast MDA-MB-231 and human cervical cancer cells (HeLa), to highlight the advantages of the construct. Overall, facile fabrication and functionalization of a maleimide group containing rGO-based functional material with potential for applications in many areas is outlined.

\section{Experimental Section}

\subsection{Materials}

$N$-Hydroxysuccinimide (NHS) was purchased from Alfa Aeser. $N, N^{\prime}-$ Dicyclohexylcarbodiimide (DCC), 4-(dimethylamino)pyridine (DMAP), dopamine hydrochloride, triethylamine (TEA), $\gamma$-aminobutyric acid, l-glutathione reduced, 6(ferrocenyl)hexanethiol, graphite powder $(<20 \mu \mathrm{m})$ and hydrazine monohydrate were purchased from Sigma-Aldrich. 4-(exo-3,5-Dioxo-10-oxa-4-aza-tricyclo[5.2.1.0]dec-8-en-4yl)-butyric acid (furan-protected maleimide containing acid) was synthesized according to a previous report.(30) Bags with regenerated cellulose dialysis membranes (Spectra/Por Biotech, molecular weight cut-offs $10 \mathrm{kDa}$ ) were obtained from Spectrum Laboratories. Purification by silica gel column was done using silica gel 60 (Merck). Purity of the compounds was determined using thin-layer chromatography on the silica-coated aluminum plates (Kieselgel 60 F254, Merck). Methanol, tetrahydrofuran, and dimethylformamide (DMF) were bought from Merck. Anhydrous toluene from SciMatCo system was used, and other solvents were stored on the molecular sieves when needed. Graphene oxide was bought from Graphenea, Spain.

\subsection{Preparation of Reduced Graphene Oxide (rGO)}

GO aqueous suspension $\left(150 \mathrm{mg}, 3 \mathrm{mg} \mathrm{mL}^{-1}\right)$ was sonicated and hydrazine hydrate $(50 \mu \mathrm{L}$, $1.03 \mathrm{mmol}$ ) added to this suspension. The mixture was heated for $24 \mathrm{~h}$ at $100{ }^{\circ} \mathrm{C}$ and $\mathrm{rGO}$ slowly precipitated out. The desired material was obtained by filtering with a poly(vinylidene difluoride) membrane $(0.45 \mu \mathrm{m}$ pore size $)$, rinsed with water $(20 \mathrm{~mL} \times 5)$ and methanol $(20$ $\mathrm{mL} \times 5$ ), followed by drying in an oven.

\subsection{Synthesis of Maleimide-Containing Dopamine (dopa-MAL)}

\subsubsection{Protected Maleimide-Containing Dopamine (dopa-pMAL)}

Furan-protected maleimide-containing acid (2.45 g, $9.76 \mathrm{mmol})$, NHS (1.18 g, $10.25 \mathrm{mmol})$, and DMAP $(0.24 \mathrm{~g}, 1.95 \mathrm{mmol})$ were dissolved in DMF $(15 \mathrm{~mL})$ in a round-bottom flask at 0 ${ }^{\circ} \mathrm{C}$. DCC dissolved in $5 \mathrm{~mL}$ of DMF was subsequently added to this solution dropwise. After stirring at $0{ }^{\circ} \mathrm{C}$ for $15 \mathrm{~min}$, the reaction was left to proceed at room temperature for $16 \mathrm{~h}$. The solvent was removed in vacuo and the product (NHS ester of the acid) was extracted with $\mathrm{NaHCO}_{3}$. This activated ester was used without further purification. Dopamine, $\mathrm{HCl}(1.43 \mathrm{~g}$, $7.54 \mathrm{mmol})$, and TEA (1.09 g, $10.8 \mathrm{mmol})$ were mixed in $10 \mathrm{~mL}$ of DMF with magnetic stirring for $15 \mathrm{~min}$. The DMF solution of the activated ester $(2.5 \mathrm{~g}, 7.18 \mathrm{mmol})$ was added to the mixture and stirred at room temperature for $24 \mathrm{~h}$. The solvent was partially evaporated 4

DOI: 10.1021/acsami.7b08433 - Journal: ACS Appl. Mater. Interfaces - Post-print 
$(\approx 1-2 \mathrm{~mL})$ and $1 \mathrm{M} \mathrm{HCl}$ solution $(50 \mathrm{~mL})$ was added to the concentrated solution. It was extracted with EtOAc. The organic phase was collected and dried over $\mathrm{Na}_{2} \mathrm{SO}_{4}$. Column chromatography using $\mathrm{CH}_{2} \mathrm{Cl}_{2}$ /methanol (10:1) was employed to obtain the pure product (1.28 g, yield: $82 \%)$.

\subsubsection{Maleimide Group Activation via Retro Diels-Alder Reaction (dopa-MAL)}

Furan-maleimide adduct-containing dopamine $(1.0 \mathrm{~g})$ in anhydrous toluene $(150 \mathrm{~mL})$ was heated under nitrogen protection at $110{ }^{\circ} \mathrm{C}$ for $10 \mathrm{~h}$. The solution was then cooled down to ambient temperature and toluene was removed via rotary evaporation, yielding maleimideappended dopamine (dopa-MAL) (0.80 g, yield: 97\%).

\subsection{Preparation of rGO/dopa-MAL}

To a solution of rGO in DMF $\left(1 \mathrm{mg} \mathrm{mL}^{-1}\right)$, dopa-MAL $(6.3 \mathrm{mM})$ was added and the mixture ultrasonicated for $3 \mathrm{~h}$ at room temperature. Maleimide-functionalized rGO was collected by centrifugation at $13000 \mathrm{rpm}$ for $30 \mathrm{~min}$ and washed with DMF to remove all of the unbound dopa-MAL compounds. The functionalized rGO was then dried under vacuum.

\subsection{Functionalization of rGO/dopa-MAL via Thiol-Ene Michael Addition Reactions}

\subsubsection{Glutathione and 6-(Ferrocenyl)hexanethiol Linking}

Dispersion of rGO/dopa-MAL in DMF $\left(1 \mathrm{mg} \mathrm{mL}^{-1}\right)$ was mixed with glutathione $(10 \mathrm{mM})$ and sonicated for $6 \mathrm{~h}$ at room temperature. The product rGO/dopa-Mal-glutathione was collected by centrifugation at $13000 \mathrm{rpm}$ for $30 \mathrm{~min}$. Similarly, 6-(ferrocenyl)hexanethiol (10 mM) was attached to rGO/dopa-MAL (1 $\mathrm{mg} \mathrm{mL}^{-1}$ DMF solution) under ultrasonication for $6 \mathrm{~h}$ at room temperature. Purified rGO/dopa-MAL-ferrocene was obtained by centrifugation at $13000 \mathrm{rpm}$ for $30 \mathrm{~min}$.

\subsection{2. c(RGDfC) Attachment to rGO/dopa-MAL}

$\mathrm{c}$ (RGDfC) (4 mM) was added to $1 \mathrm{mg} \mathrm{mL}^{-1}$ DMF dispersion of rGO/dopa-MAL and the mixture sonicated for $12 \mathrm{~h}$ at room temperature. The nonconjugated peptide was removed by dialyzing (using MWCO $10000 \mathrm{Da}$ membrane) against water for $48 \mathrm{~h}$ to yield rGO/dopaMAL-c(RGDfC).

\subsection{Quantification of Peptide and DOX Loading}

\subsubsection{Peptide Quantification Using Bicinchoninic Acid (BCA) Assay}

The amount of peptide $\mathrm{c}(\mathrm{RGDfC})$ in $\mathrm{rGO} /$ dopa-MAL-c(RGDfC) was measured using a BCA kit (ThermoScientific) using a protocol provided by the manufacturer. 


\subsubsection{Drug Loading}

Peptide-modified rGO was dispersed in water at $0.5 \mathrm{mg} \mathrm{mL}^{-1}$. Doxorubicin hydrochloride $(4.2 \mathrm{mM})$ was added to the dispersion and left to stir for $12 \mathrm{~h}$ at ambient temperature. The solution was centrifuged to remove free DOX from the DOX-loaded rGO/dopa-MALc(RGDfC) nanoconjugate.

\subsection{Characterization}

Full details of the characterization techniques and instrumentation used in this study can be found in the Supporting Information.

\subsection{Cell Viability and Internalization}

The HeLa cell line derived from cervical carcinoma (ATCC CCL-2, ECACC, Sigma-Aldrich, Saint-Quentin Fallavier, France) and the MDA-MB-231 cell line derived from human breast adenocarcinoma (ATCC HTB-26, ECACC, Sigma-Aldrich, Saint-Quentin Fallavier, France) were used. Dulbecco's modified Eagle's medium (DMEM, Gibco) containing $10 \%$ fetal bovine serum (FBS, Gibco) and 1\% penicillin-streptomycin (Gibco) were used to culture and maintain the cells in a humidified incubator at $37{ }^{\circ} \mathrm{C}$ and $5 \% \mathrm{CO}_{2}$.

\subsubsection{Cell Viability upon Treatment with rGO/dopa-MAL-c(RGDfC)}

A 96-well plate was used to seed cells at a density of $10^{4}$ cells/well and grown for $24 \mathrm{~h}$ prior to assay. A fresh medium containing rGO/dopa-MAL-c(RGDfC) was used to replace the culture medium. After $48 \mathrm{~h}$, the old medium was aspirated, washed with phosphate-buffered saline (PBS), and replaced with new medium. Cellular viability was measured using Uptiblue (Interchim) method. Briefly, $10 \mu \mathrm{L}$ of the Uptiblue solution were added to the wells containing $100 \mu \mathrm{L}$ of DMEM with 10\% FBS and the plate was incubated for $4 \mathrm{~h}$ in the incubator. The fluorescence of each well (exc. $540 \mathrm{~nm} / \mathrm{em} .590 \mathrm{~nm}$ ) was obtained with a plate reader. Experimental runs were repeated five times. The average absorbance of the untreated cells was considered as $100 \%$ viability.

\subsubsection{Cell Viability of DOX-Loaded rGO/dopa-MAL-c(RGDfC) under Passive and Active Conditions}

Cells were seeded in a 24 -well plate $\left(10^{5}\right.$ cells/well $)$ and grown for $24 \mathrm{~h}$ prior to assay. For passive release of DOX, the cell culture medium was renewed with a fresh medium that contains DOX-loaded rGO/dopa-MAL-c(RGDfC) at $\mathrm{pH}$ 7.4. After $48 \mathrm{~h}$, the old medium was removed, washed with PBS, and replaced with a fresh medium. The cell viability was measured using Uptiblue method as described above. For active release of DOX, the culture medium was replaced with the medium containing DOX-loaded rGO/dopa-MAL-c(RGDfC). After $6 \mathrm{~h}$, each well was illuminated with a continuous laser at $980 \mathrm{~nm}$ at various power densities (1-4 $\mathrm{W} \mathrm{cm}^{-2}$ ) for $10 \mathrm{~min}$. During the same time, thermal images were taken with an IR camera. The cell viability was evaluated after additional $18 \mathrm{~h}$ using Uptiblue method as described above. 


\section{Results and Discussions}

\subsection{Synthesis of Dopamine-Maleimide-Modified reduced graphene oxide (rGO/dopa- MAL)}

The aromatic structure of catechol units allows dopamine to develop strong $\pi$-stacking interactions with other aromatic bearing units such as rGO. Additionally, dopamine can be easily functionalized by exploiting its amine terminal functions as used here for the synthesis of dopa-MAL (Figure 1). 4-(exo-3,5-Dioxo-10-oxa-4-aza-tricyclo[5.2.1.0]dec-8-en-4-yl)butyric acid (1) was obtained according to a previously reported literature procedure.(30) Dopamine group conjugation was achieved through the reaction between NHS-activated acid of maleimide derivative (2) and dopamine. The ${ }^{1} \mathrm{H}$ NMR spectroscopy of dopa-pMAL (3) is seen in Figure S1A. Furan deprotection was achieved by heating dopa-pMAL in toluene followed by NMR spectroscopy (Figure S1B). Loss of proton resonances at 2.84, 5.23, and $6.51 \mathrm{ppm}$ belonging to the bicyclic core and emergence of a new proton resonance at $7.0 \mathrm{ppm}$ belonging to the proton on maleimide ring were indicative of effective furan deprotection. The ${ }^{13} \mathrm{C}$ NMR spectrum for unmasked maleimide-containing dopamine (dopa-MAL, 4) showed the expected resonances, particularly those from the two distinct carbonyl groups, one from the amide and the other from the imide group (Figure S1C).

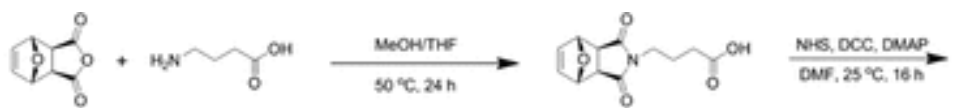

(1)

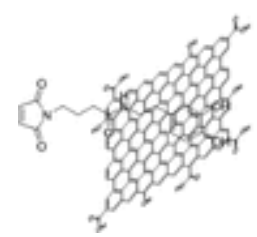

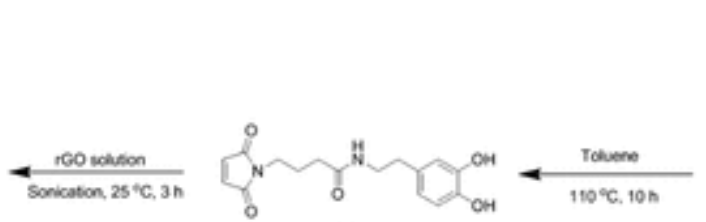

(4)

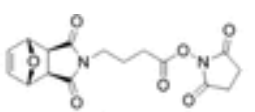

(2)

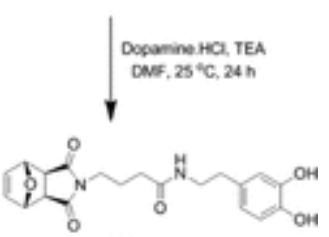

(3)

Figure 1. Synthesis of dopa-MAL (4) and its conjugation onto rGO through $\pi-\pi$ stacking interactions

Maleimide-functionalized rGO was obtained by mixing DMF dispersion of the rGO with dopa-MAL at room temperature for $3 \mathrm{~h}$ using a mass ratio of 2:1 (dopa-MAL/rGO). Fourier transform infrared (FT-IR) spectroscopy (Figure 2A) and X-ray photoelectron spectroscopy (XPS, Figure 2B) were performed for establishing the successful formation of rGO/dopaMAL. The FT-IR spectrum of rGO/dopa-MAL shows a broad band at $\sim 3400 \mathrm{~cm}^{-1}$ due to the vibration of hydroxyl groups of the dopamine ligand and the remaining $\mathrm{OH}$ groups on the rGO. The characteristic vibration band of the maleimide carbonyl group at $1696 \mathrm{~cm}^{-1}$ is clearly observed. The band at $\sim 1570 \mathrm{~cm}^{-1}$ is due to the $\mathrm{C}=\mathrm{C}$ stretching modes of the aromatic network, whereas the band at $1223 \mathrm{~cm}^{-1}$ is due to the $\mathrm{C}-\mathrm{O}$ (alkoxy) stretching modes of the rGO and the ligand. The absorption bands at 2922 and $2859 \mathrm{~cm}^{-1}$ correspond to the $\mathrm{CH}$ and $\mathrm{CH}_{2}$ stretching vibrations, respectively. 
(A)

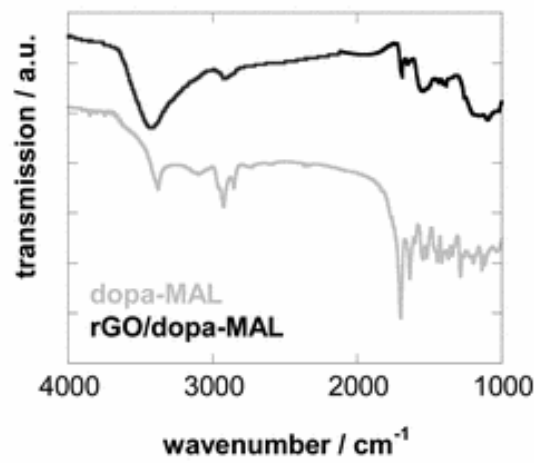

(C)

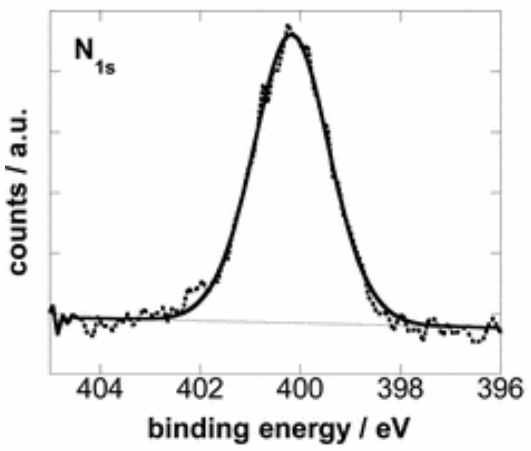

(B)

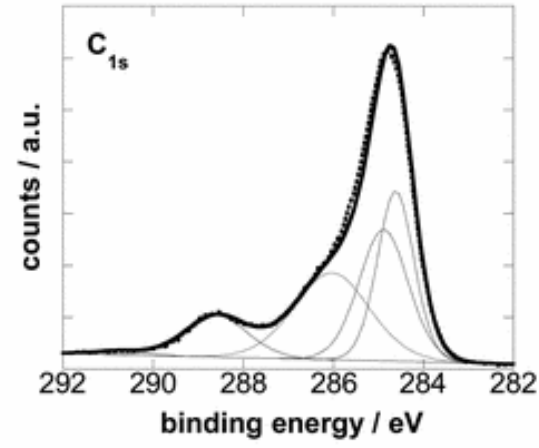

(D)

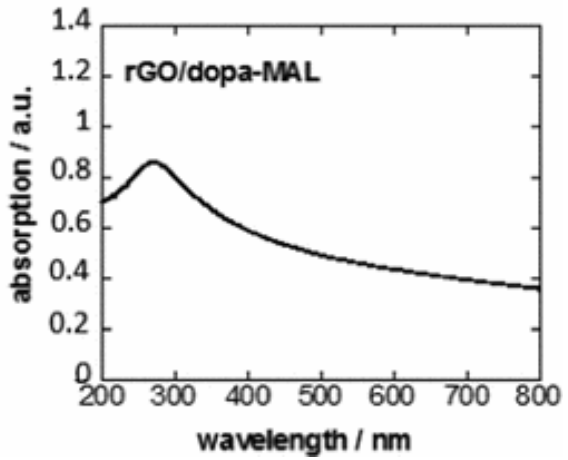

Figure 2. (A) FT-IR spectra of rGO/dopa-MAL (black) and dopa-MAL (gray). (B) $\mathrm{C}_{1 \mathrm{~s}}$ widescan XPS spectrum of rGO/dopa-MAL. (C) $\mathrm{N}_{1 \mathrm{~s}}$ wide-scan XPS spectrum of rGO/dopa-MAL. (D) UV-vis of rGO/dopa-MAL.

X-ray photoelectron spectroscopy (XPS) analysis was performed in addition to gain additional information on the rGO/dopa-MAL chemical composition (Figure 2B). The XPS survey spectrum displays bands due to $\mathrm{C}_{1 \mathrm{~s}}, \mathrm{O}_{1 \mathrm{~s}}$, and $\mathrm{N}_{1 \mathrm{~s}}$ (Table 1), in good agreement with the composition of the functionalized $\mathrm{rGO}$. The $\mathrm{C}_{1 \mathrm{~s}}$ high-resolution spectrum can be deconvoluted into bands at $284.5 \mathrm{eV}\left(\mathrm{C}-\mathrm{C} \mathrm{sp}^{2}\right), 285.0 \mathrm{eV}(\mathrm{C}-\mathrm{H} / \mathrm{C}-\mathrm{C}), 286.1 \mathrm{eV}(\mathrm{C}-\mathrm{O}), 288.2$ $\mathrm{eV}(\mathrm{N}-\mathrm{C}=\mathrm{O}, \mathrm{C}=\mathrm{O})$, and $290.3 \mathrm{eV}(\mathrm{COOH})$. The presence of $\mathrm{N}_{1 \mathrm{~s}}$ is attributed to the incorporation of maleimide onto the rGO sheets. The band at $400.2 \mathrm{eV}$ in the $\mathrm{N}_{1 \mathrm{~s}}$ high resolution (Figure 2C) corresponds to the $\mathrm{N}-\mathrm{C}=\mathrm{O}$ bonds in the rGO/dopa-MAL nanocomposite. The UV-vis spectrum of a water dispersion of rGO/dopa-MAL (Figure 2D) exhibits an absorption maximum at $269 \mathrm{~nm}$, characteristic of the $\mathrm{sp}^{2}$ hybridized structure together with a prolonged absorption tail in the NIR.

Table 1. Determination of the Atomic Percentages of Elements by the XPS Analysis

\begin{tabular}{|l|l||l||l||l|l|}
\hline \multicolumn{1}{|c|}{ composite } & $\mathbf{C}_{\mathbf{1 s}}$ atom $\%$ & $\mathbf{O}_{\mathbf{1 s}}$ atom $\%$ & $\mathbf{N}_{\mathbf{1 s}}$ atom $\%$ & $\mathbf{S}_{\mathbf{2 p}}$ atom & $\mathbf{F e}_{\mathbf{2 p}}$ atom $\%$ \\
\hline \hline rGO/dopa-MAL & 81.84 & 14.86 & 3.30 & 0 & 0 \\
\hline $\begin{array}{l}\text { rGO/dopa-MAL- } \\
\text { glutathione }\end{array}$ & 81.03 & 11.17 & 6.6 & 1.2 & 0 \\
\hline rGO/dopa-MAL-ferrocene & 81.6 & 12.00 & 3.30 & 1.5 & 1.6 \\
\hline
\end{tabular}




\subsection{Thiol-Ene Michael Addition Reaction on rGO/dopa-MAL}

The possibility to integrate thiol-containing ligands onto rGO/dopa-MAL was investigated by the conjugation of glutathione and 6-(ferrocenyl)hexanethiol via Michael addition reaction (Scheme 1). Both conjugations were carried out in DMF at room temperature for $6 \mathrm{~h}$, and the attachment was confirmed by XPS and FT-IR spectroscopy. The presence of $S_{2 p}$ indicates the successful linking of glutathione or ferrocene onto the $\mathrm{rGO}$ /dopa-MAL nanocomposite (Table 1). The exact binding constant is not determined for the rGO/dopa-MAL system due to its heterogeneous nature. No significant decrease in nitrogen atom content was observed in the XPS analysis of the product obtained after conjugation with ferrocene thiol, thus indicating that the maleimide-containing ligands do not detach from the rGO surface during these steps (Table 1). Figure 3A depicts the high-resolution XPS spectrum of the $S_{2 p}$ core-level spectra of rGO/dopa-MAL-glutathione and $\mathrm{rGO}$ /dopa-MAL-ferrocene. Both spectra can be fitted with two peaks at $164.2 \mathrm{eV}\left(\mathrm{S}_{2 \mathrm{p} 3 / 2}\right)$ and $165.3 \mathrm{eV}\left(\mathrm{S}_{2 \mathrm{p} 1 / 2}\right)$ due to $\mathrm{S}-\mathrm{C}$ bond formation with no oxidized sulfur being present, underlining the covalent integration of the thiol-bearing ligands. As a control experiment, the rGO was reacted with glutathione under the same conditions and the product was analyzed by XPS. The absence of $S_{2 p}$ component in the XPS spectrum clearly indicates that glutathione physisorption does not take place (or very limited) under our experimental conditions. The same is true for 6-(ferrocenyl)hexanethiol-modified rGO/dopaMAL. The presence of $\mathrm{Fe}_{2 \mathrm{p}}$ at $\approx 710 \mathrm{eV}$ shows in addition the integration of ferrocene units onto the matrix (Figure 3B). The $\mathrm{Fe}_{2 \mathrm{p}}$ high-resolution XPS spectrum comprises two bands at 711.7 and $725.6 \mathrm{eV}$ due to $\mathrm{Fe}_{2 \mathrm{p} 3 / 2}$ and $\mathrm{Fe}_{2 \mathrm{p} 1 / 2}$, respectively, of the $\mathrm{Fe}$ moiety in the (III) oxidation state.(31)

(A)

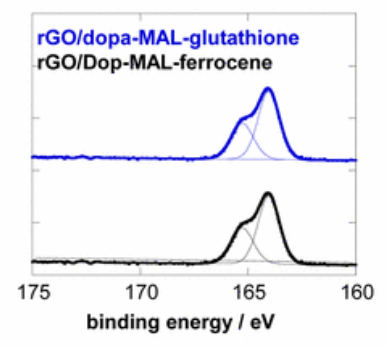

(C)

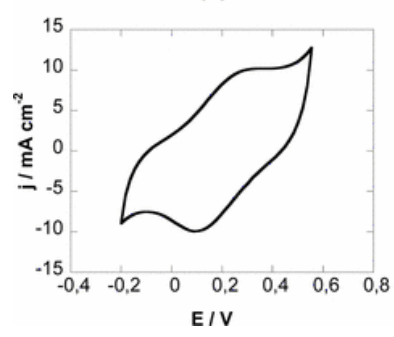

(B)

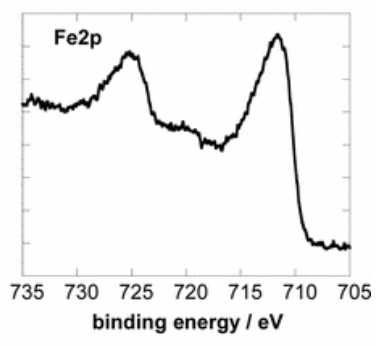

(D)

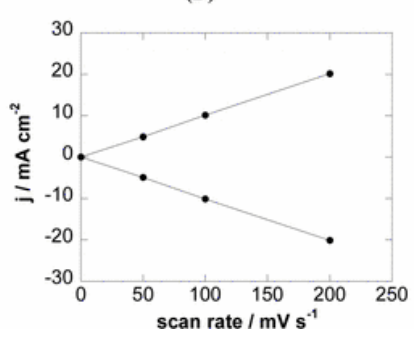

Figure 3. (A) $S_{2 p}$ high-resolution XPS spectra of rGO/dopa-MAL-glutathione (blue) and rGO/dopa-MAL-ferrocene (black). (B) $\mathrm{Fe}_{2 p}$ high-resolution XPS spectrum of rGO/dopaMAL-ferrocene. (C) Cyclic voltammogram of rGO/dopa-MAL-ferrocene in tetraethyl ammonium hexafluorophosphate $\left(\mathrm{TEAPF}_{6}\right) / \mathrm{DMF}(0.1 \mathrm{M})$, scan rate $100 \mathrm{mV} \mathrm{s}^{-1}$. (D) Change in the current density as a function of scan rate. 
In addition, the ferrocene-modified $\mathrm{rGO}$ /dopa-MAL was probed by cyclic voltammetry (CV) in $0.1 \mathrm{M}$ tetraethyl ammonium hexafluorophosphate $\left(\mathrm{TEAPF}_{6}\right)$ in DMF (Figure $\left.3 \mathrm{C}\right)$. The presence of the redox peak with a peak separation of $164 \mathrm{mV}$ and $E^{0} \approx 0.18 \mathrm{~V}$ versus $\mathrm{Ag} / \mathrm{AgCl}$ evidences the incorporation of ferrocene groups on the $\mathrm{rGO} / \mathrm{dopa}-\mathrm{MAL}$. The peak current change recorded as a function of the scan rate suggests that the ferrocene units are immobilized on the surface rather than being adsorbed. Figure $3 \mathrm{D}$ shows that the anodic and cathodic peak currents scale linearly with the scan rate, indicating a surface redox process. The loading of attached ferrocene onto the rGO surface via thiol-ene reaction was calculated according to $\Gamma=Q_{\mathrm{A}} / n F A$, where the Faraday constant is represented by $F, n$ is the number of exchanged electrons $(n=1), A$ is the area of the surface $\left(A=0.12 \mathrm{~cm}^{2}\right)$, and $Q_{\mathrm{A}}$ is the transferred anodic charge. A surface coverage of $\Gamma=4.5 \times 10^{-10} \mathrm{~mol} \mathrm{~cm} \mathrm{c}^{-2}\left(2.71 \times 10^{14}\right.$ molecules $\mathrm{cm}^{-2}$ ) is determined, being similar to that determined for the ferrocene "clicked" to diamond interfaces(31) and 6-(ferrocenyl)hexanethiol immobilized on rGO/alkynyldopamine through thiol-yne reaction.(16)

\subsection{Fabrication of Multifunctional Scaffold: Doxorubicin-Loaded rGO/dopa-MAL- c(RGDfC)}

After the successful demonstration of facile covalent functionalization of the maleimidecontaining rGO, this scaffold was investigated for its potential to target cancer cells by covalently linking to the maleimide-functionalized rGO a cyclic peptide containing the sequence $\mathrm{c}(\mathrm{RGDfC})$, known to target the integrin receptors that are often overexpressed in various types of cancer (Figure 4A). Attachment of the thiol-containing peptide was undertaken in DMF under ambient conditions, followed by dialysis against water to remove any unbound peptide. The peptide attachment was confirmed by using the BCA protein assay kit. The amount of attached peptide on rGO/dopa-MAL was determined to be $263 \mu \mathrm{g} \mathrm{mg}^{-1}$ by using the calibration plot obtained from the UV absorbance data of the peptide solution standards at $562 \mathrm{~nm}$ (see SI, Figure S2). The cytotoxicity of rGO/dopa-MAL-c(RGDfC) was assessed using the Uptiblue assay on the human breast MDA-MB-231 and human cervical HeLa cancer cells (Figure 4B). The rGO/dopa-MAL-c(RGDfC) material does not show damage to the two cell lines at the concentration of $0-100 \mu \mathrm{g} \mathrm{mL}^{-1}$ after $48 \mathrm{~h}$ incubation, illustrating the suitability of the material as a drug delivery platform. 


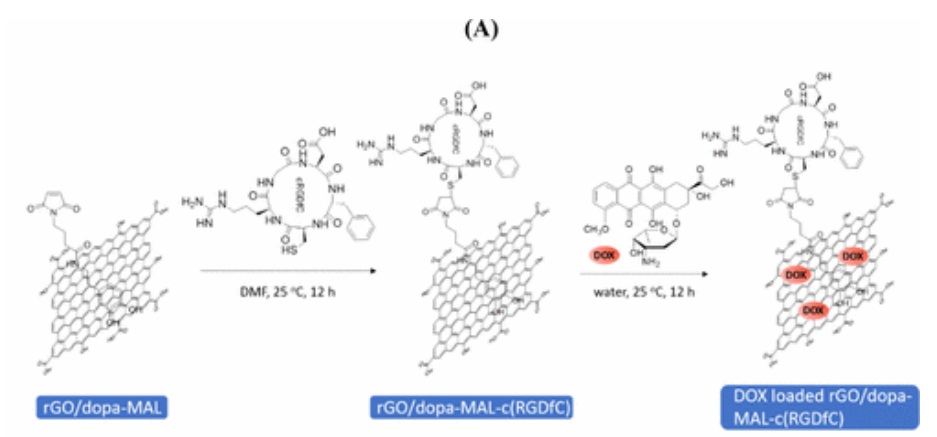

(B)

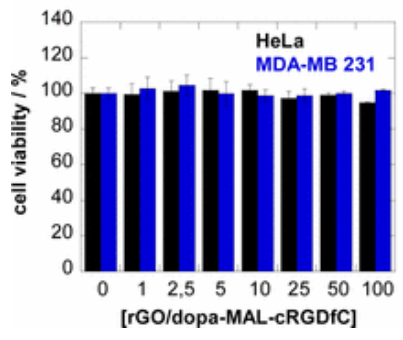

(C)

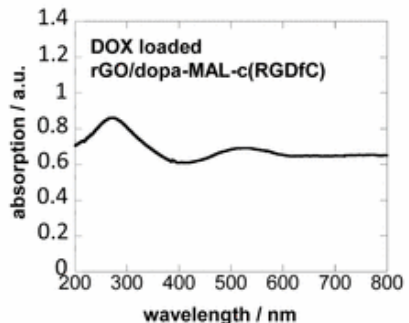

Figure 4. Formulation of doxorubicin-loaded rGO/dopa-MAL-c(RGDfC): (A) Schematic of the attachment of targeting peptide to $\mathrm{rGO} /$ dopa-MAL via Michael addition followed by the noncovalent integration of doxorubicin. (B) Cell viability of different concentrations ( $\mu \mathrm{g}$ $\mathrm{mL}^{-1}$ ) of rGO/dopa-MAL-c(RGDfC) on HeLa and MDA-MB-231 cells after incubation for 48 h. (C) UV-vis spectrum of the DOX-loaded rGO/dopa-MAL-c(RGDfC).

The chemotherapy drug doxorubicin (DOX) was next loaded onto the rGO/dopa-MAL$\mathrm{c}$ (RGDfC) nanosheets by exploiting the various interactions ( $\pi$-stacking, H-bonding, hydrophobic) between DOX and rGO. The loading was carried out in water in the dark, and the unbound drug was removed through centrifugation of the dispersion at $13000 \mathrm{rpm}$ (Figure 4A). The successful loading of DOX on rGO/dopa-MAL-c(RGDfC) was evidenced by the reddish color of the solution attributed to DOX showing an absorption peak at $480 \mathrm{~nm}$ (Figure $\underline{4 C})$. The amount of DOX loaded on the matrix was determined by monitoring the UV-vis absorbance of the supernatant (see SI, Figure S3) and determined to be as $170 \mu \mathrm{g}$ DOX loaded onto $1 \mathrm{mg}$ of rGO/dopa-MAL-c(RGDfC).

\subsection{Targeted Cell-Killing Ability of DOX-Loaded rGO/dopa-MAL-c(RGDfC)}

We next evaluated the cell-killing ability of DOX-loaded rGO/dopa-MAL-c(RGDfC) on the human cervical HeLa and the human breast MDA-MB-231 cancer cells at $\mathrm{pH}$ 7.4. The HeLa cells were used as a negative control, as the nanostructures are designed to target essentially the MDA-MB-231 cancer cell line. The dose-response curves of the free DOX for HeLa and MDA-MB-231 cancer cells (Figure 5A) allow to determine the $\mathrm{IC}_{50}$ values of 2.35 and 10.5 $\mu \mathrm{M}$ for HeLa and MDA-MB-231 lines, respectively. It is, thus, clear that DOX is much less effective on the MDA-MB-231 cell line than on the HeLa and will preferentially kill HeLa cells. 
(A)

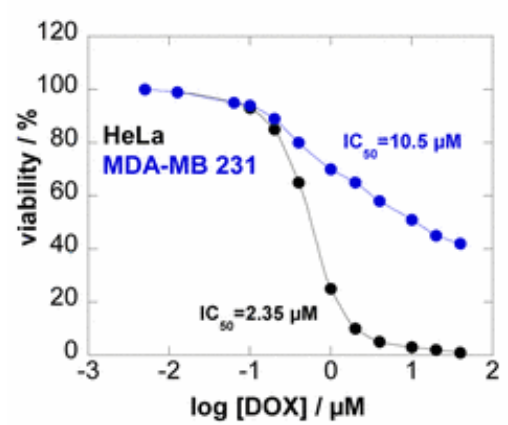

(B)

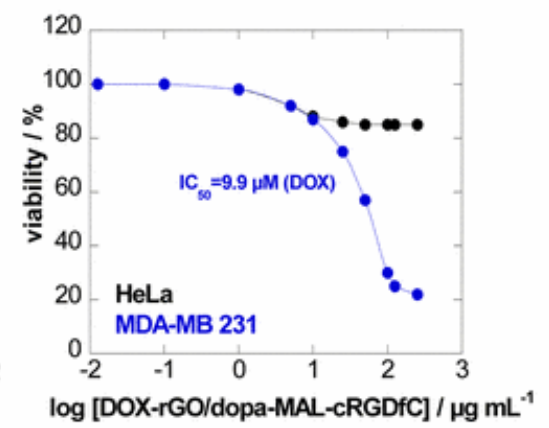

(C)

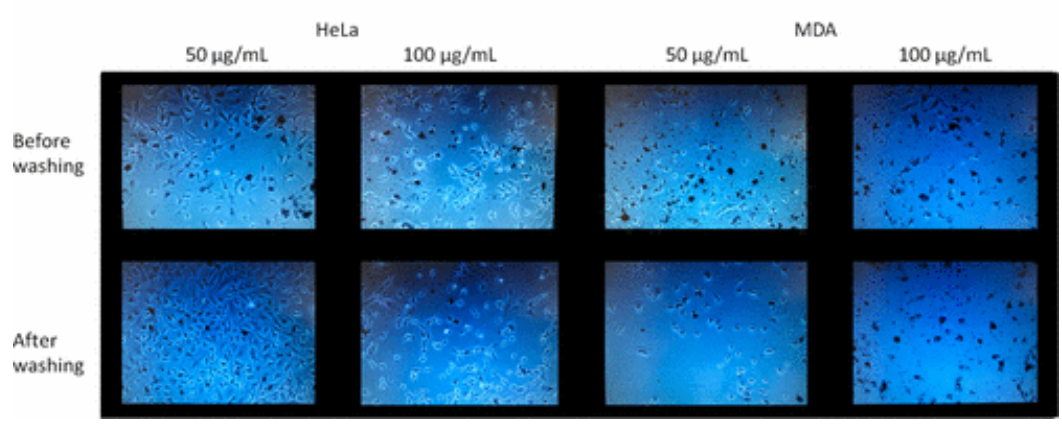

Figure 5. Dose-response curves of HeLa (black) and MDA-MB-231 (blue) cancer cells to various concentrations of (A) free DOX for $24 \mathrm{~h}$ and (B) DOX-loaded rGO/dopa-MAL$\mathrm{c}(\mathrm{RGDfC})$ nanostructures for $48 \mathrm{~h}$. (C) Optical images showing the targeting effect of DOXloaded rGO/dopa-MAL-c(RGDfC) at two different concentrations (50 and $100 \mu \mathrm{g} \mathrm{mL}^{-1}$ ) after $6 \mathrm{~h}$ incubation before and after washing with PBS.

We next evaluated the viability of HeLa and MDA-MB-231 cells upon the incubation with DOX-loaded rGO/dopa-MAL-c(RGDfC) nanostructure for $48 \mathrm{~h}$. Figure 5B suggests that under physiological $\mathrm{pH}$, the nanostructure does not show any cell-killing ability for the HeLa cells. However, $100 \mu \mathrm{g} \mathrm{mL} \mathrm{m}^{-1}$ of rGO/dopa-MAL-c(RGDfC) (corresponding to $17 \mu \mathrm{g}$ DOX) induced cell killing with an estimated $\mathrm{IC}_{50}=58 \mu \mathrm{g} \mathrm{mL} \mathrm{m}^{-1}$ for DOX-loaded rGO/dopa-MAL$\mathrm{c}($ RGDfC). Considering that $17 \mu \mathrm{g}$ DOX is integrated onto $100 \mu \mathrm{g}$ of the rGO nanosheets, this corresponds to an $\mathrm{IC}_{50}=9.9 \mu \mathrm{g} \mathrm{mL}{ }^{-1}$ for DOX in the matrix, comparable to the $\mathrm{IC}_{50}=10.5$ $\mu \mathrm{M}$ of free DOX for the same cell line (Figure 5A). The targeting effect is even more clearly pronounced, as HeLa cells are more sensitive to DOX with free DOX showing a $\approx 4$ times lower $\mathrm{IC}_{50}$ value when compared with the MDA-MB-231 cells. The optical images of both cell lines after treatment with DOX-loaded rGO/dopa-MAL-c(RGDfC) $\left(100 \mu \mathrm{g} \mathrm{mL}^{-1}\right)$ (Figure $\underline{5}$ ) demonstrate in addition the targeting effect of DOX-loaded rGO/dopa-MAL-c(RGDfC). The cell morphology of HeLa cells is preserved, whereas that of MDA-MB-231 cells is compromised. Interestingly, most DOX molecules remained attached to the rGO/dopa-MAL$\mathrm{c}(\mathrm{RGDfC})$ nanostructure and only $<1 \%$ of DOX was released from the structures after $24 \mathrm{~h}$ incubation in the physiological solution with the same ionic strength but different $\mathrm{pH}$ values. We were thus intrigued to see if the photothermal properties of the rGO/dopa-MAL$\mathrm{c}$ (RGDfC) nanosheets can further improve the cell-killing ability without losing its targeting benefit. 


\subsection{Targeted Photothermal Cell-Killing Ability of DOX-Loaded rGO/dopa-MAL- c(RGDfC)}

Graphene nanosheets, due to their good photothermal properties together with excellent loading capacity of water-insoluble cancer drugs $\underline{(10)}$ and drugs with aromatic structures $\underline{(7)}$ such as DOX, are considered as an ideal nanomaterial for the development of combined therapeutic approaches. $(32,33)$ Particularly, the photothermal properties are appealing, as the generated heat will result in the photothermal ablation of cancer cells, which is known to increase the sensitivity of chemotherapy.(34) Figure 6A depicts the heat profiles of different concentrations of DOX-loaded rGO/dopa-MAL-c(RGDfC) solutions upon irradiation for 10 min with a continuous NIR laser at $980 \mathrm{~nm}$ at various laser power densities. The temperature increase is dependent on concentration and laser power, with a $100 \mu \mathrm{g} \mathrm{mL}^{-1}$ DOX-loaded $\mathrm{rGO} /$ dopa-MAL-c(RGDfC) heating from 22 to $45^{\circ} \mathrm{C}$ in $10 \mathrm{~min}$ using a laser power of $4 \mathrm{~W}$ $\mathrm{cm}^{-2}$, being sufficient to induce cancer cell death. In addition, the generated heat gradient changes the affinity of DOX to rGO/dopa-MAL-c(RGDfC). As seen from Figure 6B, a pHand laser-power-dependent DOX release takes place. The release is rather moderate from 0.17 $\mu \mathrm{g} \mathrm{mL} \mathrm{g}^{-1} \mathrm{DOX}$ (no light) to $2.1 \mu \mathrm{g} \mathrm{mL}^{-1}$ upon illumination at $4 \mathrm{~W} \mathrm{~cm}^{-2}$. Looking at cell viability upon light irradiation (Figure 6C,D), it becomes additionally clear that the laser power densities of $4 \mathrm{~W} \mathrm{~cm}^{-2}$ override the targeting approach, resulting in nontargeted cell killing. With a laser power of $2 \mathrm{~W} \mathrm{~cm}^{-2}$, the DOX-loaded rGO/dopa-MAL-c(RGDfC) shows a somewhat improved $\mathrm{IC}_{50}=48 \mu \mathrm{g} \mathrm{mL}{ }^{-1}$ for MDA-MB-231 cells, corresponding to DOX $\mathrm{IC}_{50}$ $=8.2 \mu \mathrm{g} \mathrm{mL}^{-1}$ and keeping a complete targeting capability.

(A)

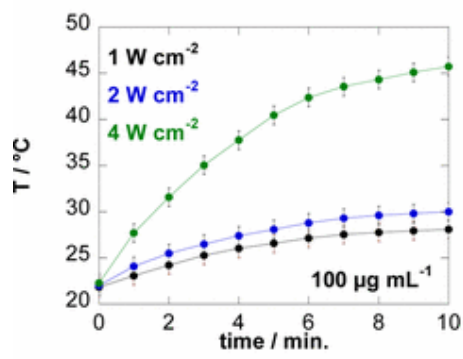

(C)

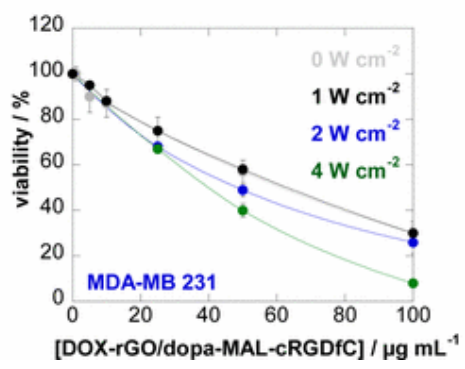

(B)

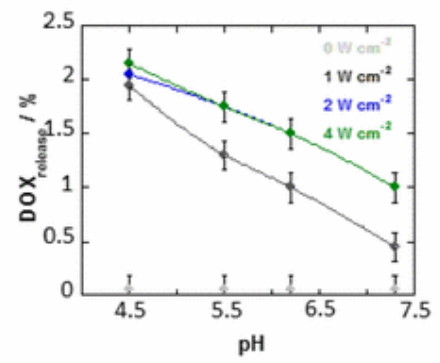

(D)

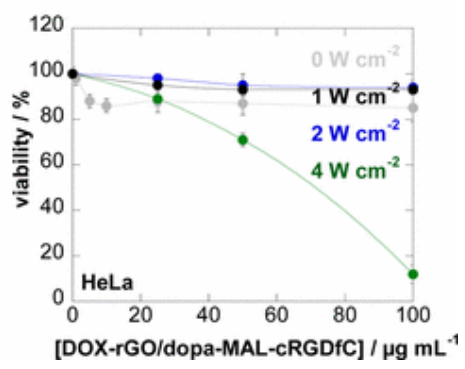

Figure 6. (A) Photothermal heating profiles of DOX-loaded rGO/dopa-MAL-cRGDfC (100 $\mu \mathrm{g} \mathrm{mL} \mathrm{m}^{-1}$ ) using a $980 \mathrm{~nm}$ laser at different laser power densities. (B) DOX amount released from the DOX-loaded rGO/dopa-MAL-cRGDfC (17 $\mu \mathrm{g}$ DOX for $100 \mu \mathrm{g}$ rGO/dopa-MALcRGDfC) matrix. (C) Cell viability of MDA-MB-231 cells after irradiation for $10 \mathrm{~min}$ at 980 $\mathrm{nm}$ with different laser power densities after $6 \mathrm{~h}$ incubation and then additional $18 \mathrm{~h}$ incubation. (D) Cell viability of HeLa cells after irradiation at $980 \mathrm{~nm}$ for $10 \mathrm{~min}$ at different laser power densities after $6 \mathrm{~h}$ incubation and then additional $18 \mathrm{~h}$ incubation. 


\section{Conclusions}

In conclusion, we have demonstrated the interest of a maleimide-containing catechol (dopaMAL) ligand as a versatile surface anchor onto the rGO nanosheets. The rGO/dopa-MALmodified nanosheets can be easily modified with the thiol-containing molecules under ambient metal-free conditions. We could show that this approach is not only effective for model molecules such as glutathione and ferrocene containing a thiol group, but it is also adaptable to the covalent linking of thiol-containing tripeptides, such as the cancer cell targeting peptide $\mathrm{c}(\mathrm{RGDFC})$. The specific cell targeting and ablation properties of DOXloaded rGO/dopa-MAL-c(RGDfC) nanosheets was confirmed through the cell viability of human breast MDA-MB-231 adenocarcinoma cells after $48 \mathrm{~h}$ incubation with the nanostructures and of the human cervical HeLa cancer cells as the negative control. The HeLa cells remained unaffected by even high concentrations of DOX-loaded rGO/dopa-MAL$\mathrm{c}$ (RGDfC). The nanostructures were, however, effective on MDA-MB-231 cells with an $\mathrm{IC}_{50}$ $=58 \mu \mathrm{g} \mathrm{mL}^{-1}$ for the DOX-loaded $\mathrm{rGO} /$ dopa-MAL-c(RGDfC), corresponding to an $\mathrm{IC}_{50}=9.9$ $\mu \mathrm{g} \mathrm{mL} \mathrm{m}^{-1}$ for DOX in the matrix. Slight improvements were achieved upon $980 \mathrm{~nm}$ irradiation of the DOX-loaded rGO/dopa-MAL-c(RGDfC) in the presence of MDA-MB-231 cells for 10 min at $2 \mathrm{~W} \mathrm{~cm}^{-2}$, whereas high laser power densities proved detrimental for the targeting ability of the $c$ (RGDfC) peptide-containing construct.

\section{Acknoledegment}

The Centre National de la Recherche Scientifique (CNRS), the University Lille 1, the Hautsde-France region, the CPER "Photonics for Society," the Agence Nationale de la Recherche (ANR), and the EU union through FLAG-ERA JTC 2015-Graphtivity, and the Marie Sklodowska-Curie action (H2020-MSCA-RISE-2015, PANG-690836) are acknowledged for the financial support.

\section{References}

1. Teodorescu, F.; Rolland, L.; Ramarao, V.; Abderrahmani, A.; Mandler, D.; Boukherroub, R.; Szunerits, S. Electrochemically Triggered Release of Human Insulin from an Insulin-Impregnated Reduced Graphene Oxide Modified Electrode Chem. Commun. 2015, 51, 14167- 14170 DOI: 10.1039/c5cc05539c

2. Szunerits, S.; Teodorescu, F.; Boukherroub, R. Electrochemically Triggered Release of Drugs Eur. Polym. J. 2016, 83, 467- 477 DOI: 10.1016/j.eurpolymj.2016.03.001

3. Boulahneche, S.; Jijie, R.; Barras, A.; Chekin, F.; Singh, S. K.; Bouckaert, J.; Medjram, M. S.; Kurungot, S.; Boukherroub, R.; Szunerits, S. On Demand Electrochemical Release of Drugs from Porous Reduced Graphene Oxide Modified Flexible Electrodes J. Mater. Chem. B 2017, 5, 6557- 6565 DOI: 10.1039/C7TB00687J

4. Hu, S. H.; Fang, R. H.; Chen, Y. W.; Liao, B. J.; Chen, I. W.; Chen, S. Y. Photoresponsive Protein-Graphene-Protein Hybrid Capsules with Dual Targeted Heat-Triggered Drug Delivery Approach for Enhanced Tumor Therapy Adv. Funct. Mater. 2014, 24, 4144- 4155 DOI: 10.1002/adfm.201400080

5. Wang, C.; Mallela, J.; Garapati, U. S.; Ravi, S.; Chinnasamy, V.; Girard, Y.; Howell, M.; Mohapatra, S. M. A Chitosan-Modified Graphene Nanogel for 
Noninvasive Controlled Drug Release Nanomedicine 2013, 9, 903- 911 DOI: 10.1016/j.nano.2013.01.003

6. Teodorescu, F.; Oz, Y.; Quéniat, G.; Abderrahmani, A.; Foulon, C.; Lecoeur, M.; Sanyal, R.; Sanyal, A.; Boukherroub, R.; Szunerits, S. Photothermally Triggered On-demand Insulin Release from Reduced Graphene Oxide Modified Hydrogels J. Controlled Release 2017, 246, 64- 173 DOI: 10.1016/j.jconrel.2016.10.028

7. Teodorescu, F.; Quéniat, G.; Foulon, C.; Lecoeur, M.; Barras, A.; Boulahneche, S.; Medjram, M. S.; Hubert, T.; Abderrahmani, A.; Boukherroub, R.; Szunerits, S. Transdermal Skin Patch Based on Reduced Graphene Oxide: A New Approach for Photothermal Triggered Permeation of Ondansetron Across Porcine Skin J. Controlled Release 2017, 245, 137- 146 DOI: 10.1016/j.jconrel.2016.11.029

8. Goenka, S.; Sant, V.; Sant, S. Graphene-based Nanomaterials for Drug Delivery and Tissue Engineering J. Controlled Release 2014, 173, 75- 88 DOI: 10.1016/j.jconrel.2013.10.017

9. Matteini, P.; Tatini, F.; Cavigli, L.; Ottaviano, S.; Ghini, G.; Pini, R. Graphene as a Photothermal Switch for Controlled Drug Release Nanoscale 2014, 6, 7947- 7953 DOI: $10.1039 / \mathrm{c} 4 \mathrm{nr} 01622 \mathrm{j}$

10. Turcheniuk, K.; Dumych, T.; Bilyy, R.; Turcheniuk, V.; Bouckaert, J.; Vovk, V.; Chopyak, V.; Zaitsev, V.; Mariot, P.; Prevarskaya, N.; Boukherroub, R.; Szunerits, S. Plasmonic Photothermal Cancer Therapy with Gold Nanorods/Reduced Graphene Oxide Core/Shell Nanocomposites RSC Adv. 2016, 6, 1600- 1610 DOI: 10.1039/C5RA24662H

11. Guo, C. X.; Ng, S. R.; Khoo, S. Y.; Zheng, X.; Chen, P.; Li, C. M. RGD-Peptide Functionalized Graphene Biomimetic Live-Cell Sensor for Real-Time Detection of Nitric Oxide Molecules ACS Nano 2012, 6, 6944- 6951 DOI: 10.1021/nn301974u

12. Xu, L. Q.; Wang, L.; Zhang, B.; Lim, C. H.; Chen, Y.; Neoh, K. G.; Kang, E.; Fu, G. D. Functionalization of Reduced Graphene Oxide Nanosheets via Stacking Interactions with the Fluorescent and Water-Soluble Perylene Bisimide-Containing Polymers Polymer 2011, 52, 2376-2383 DOI: 10.1016/j.polymer.2011.03.054

13. Kaminska, I.; Barras, A.; Coffinier, Y.; Lisowski, W.; Roy, S.; NiedziolkaJonsson, J.; Woisel, P.; Lyskawa, J.; Opallo, M.; Siriwardena, A.; Boukherroub, R.; Szunerits, S. Preparation of a Responsive Carbohydrate-Coated Biointerface Based on Graphene/Azido-Terminated Tetrathiafulvalene Nanohybrid Material ACS Appl. Mater. Interfaces 2012, 4, 5386- 5393 DOI: 10.1021/am3013196

14. Kaminska, I.; Das, M. R.; Coffinier, Y.; Niedziolka-Jonsson, J.; Sobczak, J.; Woisel, P.; Lyskawa, J.; Opallo, M.; Boukherroub, R.; Szunerits, S. Reduction and Functionalization of Graphene Oxide Sheets Using Biomimetic Dopamine Derivatives in One Step ACS Appl. Mater. Interfaces 2012, 4, 1016- 1020 DOI: 10.1021/am201664n

15. Kaminska, I.; Das, M. R.; Coffinier, Y.; Niedziolka-Jonsson, J.; Woisel, P.; Opallo, M.; Szunerits, S.; Boukherroub, R. Preparation of Graphene/Tetrathiafulvalene Nanocomposite Switchable Surfaces Chem. Commun. 2012, 48, 1221- 1223 DOI: 10.1039/C1CC15215G

16. Kaminska, I.; Qi, W.; Barras, A.; Sobczak, J.; Niedziolka-Jonsson, J.; Woisel, P.; Lyskawa, J.; Laure, W.; Opallo, M.; Li, M.; Boukherroub, R.; Szunerits, S. Thiolyne Click Reaction on Alkynyl-Dopamine Modified Reduced Graphene Oxide (rGO) Chem. - Eur. J. 2013, 19, 8673-8678 DOI: 10.1002/chem.201300225

17. Qu, S.; Li, M.; Xie, L.; Huang, X.; Yang, J.; Wang, N.; Yang, S. Noncovalent Functionalization of Graphene Attaching [6,6]-Phenyl-C61-butyric Acid Methyl 
Ester (PCBM) and Application as Electron Extraction Layer of Polymer Solar Cells ACS Nano 2013, 7, 4070-4081 DOI: 10.1021/nn4001963

18. Manova, R. K.; Pujari, S. P.; Weijers, C. A. G. M.; Zuilhof, H.; van Beek, T. A. Copper-Free Click Biofunctionalization of Silicon Nitride Surfaces via StrainPromoted Alkyne-Azide Cycloaddition Reactions Langmuir 2012, 28, 8651- 8663 DOI: $10.1021 / \mathrm{la3} 00921 \mathrm{e}$

19. Zhang, L.; Vilà, N.; Klein, T.; Kohring, G.-W.; Mazurenko, I.; Walcarius, A.; Etienne, M. Immobilization of Cysteine-Tagged Proteins on Electrode Surfaces by Thiol-Ene Click Chemistry ACS Appl. Mater. Interfaces 2016, 8, 17591- 17598 DOI: $10.1021 /$ acsami.6b02364

20. Escorihuela, J.; Marcelis, A. T. M.; Zuilhof, H. Metal-Free Click Chemistry Reactions on Surfaces Adv. Mater. Interfaces 2015, 21500135 DOI: 10.1002/admi.201500135

21. Mazur, M.; Barras, A.; Kuncser, V.; Galatanu, A.; Zaitzev, V.; Turcheniuk, K. V.; Woisel, P.; Lyskawa, J.; Laure, W.; Siriwardena, A.; Boukherroub, R.; Szunerits, S. Iron Oxide Magnetic Nanoparticles with Versatile Surface Functions Based on Dopamine Anchors Nanoscale 2013, 5, 2692- 2702 DOI: 10.1039/c3nr33506b

22. Hoyle, C. E.; Lowe, A. B.; Bowman, C. N. Thiol-Click Chemistry: A Multifaceted Toolbox for Small Molecule and Polymer Synthesis Chem. Soc. Rev. 2010, 39, 1355- 1387 DOI: 10.1039/b901979k

23. Oz, Y.; Arslan, M.; Gevrek, T. N.; Sanyal, R.; Sanyal, A. Modular Fabrication of Polymer Brush Coated Magnetic Nanoparticles: Engineering the Interface for Targeted Cellular Imaging ACS Appl. Mater. Interfaces 2016, 8, 19813- 19826 DOI: 10.1021/acsami.6b04664

24. Arslan, M.; Gevrek, T. N.; Lyskawa, J.; Szunerits, S.; Boukherroub, R.; Sanyal, R.; Woisel, P.; Sanyal, A. Bioinspired Anchorable Thiol-Reactive Polymers: Synthesis and Applications Toward Surface Functionalization of Magnetic Nanoparticles Macromolecules 2014, 47, 5124- 5134 DOI: 10.1021/ma500693f

25. Waite, C. L.; Roth, C. M. PAMAM-RGD Conjugates Enhance siRNA Delivery Through a Multicellular Spheroid Model of Malignant Glioma Bioconjugate Chem. 2009, 20, 1908- 1916 DOI: 10.1021/bc900228m

26. Xiong, X. B.; Huang, Y.; Lu, W. L.; Zhang, X.; Zhang, H.; Nagai, T.; Zhang, Q. Enhanced Intracellular Delivery and Improved Antitumor Efficacy of Doxorubicin by Sterically Stabilized Liposomes Modified with a Synthetic RGD Mimetic J. Controlled Release 2005, 107, 262-275 DOI: 10.1016/j.jconrel.2005.03.030

27. Zhu, S.; Qian, L.; Hong, M.; Zhang, L.; Pei, Y.; Jiang, Y. RGD-Modified PEGPAMAM-DOX Conjugate: In Vitro and In Vivo Targeting to Both Tumor Neovascular Endothelial Cells and Tumor Cells Adv. Mater. 2011, 23, H84- H89 DOI: 10.1002/adma.201003944

28. Zhang, L.; Zhu, S.; Qian, L.; Pei, Y.; Qiu, Y.; Jiang, Y. RGD-Modified PEGPAMAM-DOX Conjugates: In Vitro and In Vivo Studies for Glioma Eur. J. Pharm. Biopharm. 2011, 79, 232- 240 DOI: 10.1016/j.ejpb.2011.03.025

29. Luo, D.; Carter, K. A.; Miranda, D.; Lovell, J. F. Chemophototherapy: An Emerging Treatment Option for Solid Tumors Adv. Sci. 2017, 41600106 DOI: 10.1002/advs.201600106

30. Maynard, H. D.; Okada, S. Y.; Grubbs, R. H. Synthesis of Norbornenyl Polymers with Bioactive Oligopeptides by Ring-Opening Metathesis Polymerization Macromolecules 2000, 33, 6239-6248 DOI: 10.1021/ma000460c 
31. Das, M. R.; Wang, M.; Szunerits, S.; Gengembre, L.; Boukherroub, R. Clicking Ferrocene Groups to Boron-Doped Diamond Electrodes Chem. Commun. 2009, 2753- 2755 DOI: 10.1039/b901481k

32. Sneider, A.; VanDyke, D.; Paliwal, S.; Rai, P. Remotely Triggered NanoTheranostics For Cancer Applications Nanotheranostics 2017, 1, 1- 22 DOI: 10.7150/ntno. 17109

33. Chen, Y. W.; Su, Y. L.; Hu, S. H.; Chen, S. Y. Functionalized Graphene Nanocomposites for Enhancing Photothermal Therapy in Tumor Treatment Adv. Drug Delivery Rev. 2016, 105, 190- 204 DOI: 10.1016/j.addr.2016.05.022

34. Wang, Y.; Wang, K.; Zhao, J.; Liu, X.; Bu, J.; Yan, X.; Huang, R. Multifunctional Mesoporous Silica-Coated Graphene Nanosheet Used for Chemo-Photothermal Synergistic Targeted Therapy of Glioma J. Am. Chem. Soc. 2013, 135, 4799 DOI: $10.1021 / \mathrm{ja} 312221 \mathrm{~g}$ 